Original Article

\title{
Relationship between Postural Sway and Dynamic Balance in Stroke Patients
}

\author{
Kinun Cho, PT, PhD ${ }^{1)}$, Kyoungsuk Lee, PT, PhD ${ }^{2)}$, Byunguoon Lee, PT, $\mathrm{MS}^{2)}$, \\ Hwangjae Lee, PT, MS ${ }^{2)}$, Wanhee Lee, PT, PhD ${ }^{2 *}$ \\ 1) Department of Rehabilitative and Assistive Technology, National Rehabilitation Research Institute, \\ Republic of Korea \\ 2) Department of Physical Therapy, Sahmyook University: 26-21 Gongneung 2-dong, Nowon-gu, Seoul \\ 139-742, Republic of Korea
}

\begin{abstract}
Purpose] The purpose of the current study was to investigate the relationship between postural sway and dynamic balance in post stroke patients. [Subjects] Thirty-one stroke patients (20 men and 11 women; age 64.25 years; stroke duration 12.70 months; MMSE-K score 26.35) participated in this study. [Methods] This study applied a cross-sectional design. A Good Balance system was used for measurement of the postural sway velocity (anteroposterior and mediolateral) and velocity moment of subjects under the eyes open and eyes closed conditions in a standing posture. The postural sway of subjects was measured under two surface conditions (stable and unstable surfaces). [Results] On the unstable surface (foam), no significant correlation was observed between postural sway and dynamic balance except for the berg balance scale (BBS) score and anteroposterior postural sway velocity under the eyes open condition, anteroposterior postural sway velocity under the eyes closed condition, and postural sway velocity moment. In addition, in the stable condition, no significant correlation was observed between postural sway and dynamic balance. [Conclusion] Our results indicate that a decrease in postural sway does not necessarily reflect improvement of dynamic balance ability. We believe that this finding may be useful in balance rehabilitation for prevention of falls after a stroke.

Key words: Dynamic balance, Postural sway, Stroke
\end{abstract}

(This article was submitted Jun. 2, 2014, and was accepted Jun. 27, 2014)

\section{INTRODUCTIONS}

Postural control is essential in performance of independent activities of daily living in stroke patients ${ }^{1}$. Postural control is defined as the ability to maintain the center of mass (COM) within the base of support with minimal postural sway, and the sensory systems (visual, somatosensory, and vestibular systems), cognitive processing, and movement strategies are needed for maintenance of postural control $^{2)}$. In general, postural control can be classified according to static and dynamic postural control ${ }^{3)}$. Therefore, evaluation of postural control should be considered for both aspects of static and dynamic postural control. In the clinic or hospital setting, the Berg Balance Scale (BBS) and Timed Up and Go test (TUG) are used mainly for evaluation of dynamic postural control ${ }^{4,5)}$, and measurement of postural sway using a force platform is commonly used for evaluation of static postural control ${ }^{6}$.

Postural sway is the movement of the COM in a standing

*Corresponding author. Wanhee Lee (E-mail: whlee@syu. ac.kr)

(C2014 The Society of Physical Therapy Science. Published by IPEC Inc. This is an open-access article distributed under the terms of the Creative Commons Attribution Non-Commercial No Derivatives (by-ncnd) License $<$ http://creativecommons.org/licenses/by-nc-nd/3.0/>. position ${ }^{2)}$. A force platform system can provide quantifying data for postural control of subjects by measuring the postural sway ${ }^{7)}$. Previous studies reported an association of increased in postural sway with aging ${ }^{8)}$. In addition, Lajoie et al. ${ }^{9)}$ reported an association of increased postural sway with reduction of dynamic balance ability. On the other hand, some studies reported that an increase in postural sway is not necessarily an indication of poor dynamic balance ability but simply indicates static balance ability ${ }^{10,11)}$. Thus, the question of whether or not postural sway is associated with dynamic balance is still debatable. The purpose of the current study was to gain a more comprehensive understanding of the relationship between postural sway and dynamic balance in post stroke patients.

\section{SUBJECTS AND METHODS}

This study applied a cross-sectional design. Thirty-one stroke patients were recruited on a voluntary basis from an inpatient hospital. Subjects were included if (1) they had a diagnosis of stroke (cerebral cortex lesion: ischemic brain injury or intracerebral hemorrhage) based on magnetic resonance imaging or computed tomography, (2) they were able to understand and follow simple verbal instructions (Korean version of the mini-mental state examination score $>$ 24), (3) they had no known musculoskeletal conditions that would affect the ability to stand safely; and (4) they had no 
serious visual impairment or hearing disorder. The exclusion criteria were (1) participation in another study or rehabilitation program, (2) severe heart disease or uncontrolled hypertension and pain, and (3) any neurologic or orthopedic disease that might interfere with the study. All subjects participated in conventional rehabilitation programs consisting of physical and occupational therapy during hospitalization. Three of the 34 potential subjects were excluded because they met the exclusion criteria (participation in another study or uncontrolled hypertension). Ultimately, 31 subjects (20 men and 11 women; age 64.25 years; stroke duration 12.70 months; MMSE-K score 26.35) were included in this study. The subjects were briefed on the experimental procedure, and written consent forms were collected from all subjects prior to conduct of the experiment; the subjects voluntarily signed informed consent forms. Human subject ethical approval was obtained from the relevant committee of the Sahmyook University institutional review board prior to conduct of the experiment.

A Good Balance system ${ }^{\circledR}$ (Good Balance system, Metitur, Oy, Jyvaskyla, Finland) was used for measurement of postural sway velocity and velocity moment of subjects in the standing posture. According to a previous study, the Good Balance system ${ }^{\circledR}$ has adequate reliability for research and clinical use in stroke patients ${ }^{11)}$. On the basis of the coordinate values for $\mathrm{x}$ and $\mathrm{y}$, the following parameters were calculated: (1) mean speed of movement of the center of pressure (COP) in the anteroposterior (AP) direction $(\mathrm{mm} / \mathrm{s})$; (2) mean speed of movement of the COP in the mediolateral (ML) direction ( $\mathrm{mm} / \mathrm{s})$, and (3) mean velocity moment $\left(\mathrm{mm}^{2} / \mathrm{s}\right)$. Postural sway velocity moment is defined as the average horizontal area covered by movement of the center (AP and ML direction) of force per second. The force platform, which was an equilateral triangle $(800 \mathrm{~mm})$, was connected to a three-channel DC amplifier. Signals from the amplifier were converted into digital form using a 12byte converter (sampling frequency $=50 \mathrm{~Hz}$ ) and stored on the hard disk of a personal computer. For measurement of postural sway under the stable surface condition, subjects stood on the force plate with their legs spread at shoulder width and then looked at a number on a monitor three times for 30 seconds. For measurement of postural sway under the unstable surface condition, a subject stood on the force plate, which was covered with foam, with their legs spread at shoulder width and then looked at a number on a monitor three times for 30 seconds $^{11)}$. Three repeats of each measurement were performed, and the average was used in the statistical analysis. A rest period of three minutes was provided between measurements. The following instruction was communicated to the subjects in order to ask them to move their bodies as little as possible: "Please try your best to stand without swaying."

The Berg Balance Scale (BBS) and Timed Up and Go test (TUG) were used for measurement of dynamic balance ability. The BBS is a valid and reliable instrument for measurement of both the static and dynamic aspects of balance in elderly people after a stroke ${ }^{4}$. The TUG is measured as the time (seconds) required for performance of the following: stand up from a chair, walk $3 \mathrm{~m}$ at a nor-
Table 1. General characteristics and dependent variables of the subjects $(\mathrm{N}=31)$

\begin{tabular}{|c|c|}
\hline Variables & $\mathrm{M} \pm \mathrm{SD}(\%)$ \\
\hline \multicolumn{2}{|l|}{ Gender } \\
\hline Male/female (\%) & $20 / 11(64.5 / 35.5)$ \\
\hline \multicolumn{2}{|l|}{ Paretic side } \\
\hline Right/left (\%) & $25 / 6(80.6 / 19.4)$ \\
\hline \multicolumn{2}{|l|}{ Etiology } \\
\hline Infarction/hemorrhage (\%) & $18 / 13(58.1 / 41.9)$ \\
\hline Age (years) & $64.2 \pm 4.8$ \\
\hline Height (cm) & $165.3 \pm 6.2$ \\
\hline Mass (kg) & $63.5 \pm 7.5$ \\
\hline Post stroke duration (months) & $12.7 \pm 2.5$ \\
\hline MMSE-K (score) & $26.3 \pm 2.2$ \\
\hline \multicolumn{2}{|l|}{ Stable condition } \\
\hline AP-PSV(EO) (mm/s) & $7.1 \pm 2.4$ \\
\hline ML-PSV(EO) (mm/s) & $10.8 \pm 3.4$ \\
\hline $\operatorname{PSVM}(\mathrm{EO})\left(\mathrm{mm}^{2}\right)$ & $33.0 \pm 24.8$ \\
\hline AP-PSV(EC) $(\mathrm{mm} / \mathrm{s})$ & $9.2 \pm 5.1$ \\
\hline ML-PSV(EC) (mm/s) & $17.0 \pm 8.6$ \\
\hline $\operatorname{PSVM}(\mathrm{EC})\left(\mathrm{mm}^{2}\right)$ & $58.6 \pm 64.1$ \\
\hline \multicolumn{2}{|l|}{ Unstable condition } \\
\hline AP-PSV(EO) (mm/s) & $11.5 \pm 4.6$ \\
\hline ML-PSV(EO) (mm/s) & $16.5 \pm 6.6$ \\
\hline $\operatorname{PSVM}(E O)\left(\mathrm{mm}^{2}\right)$ & $71.8 \pm 38.2$ \\
\hline AP-PSV(EC) (mm/s) & $20.6 \pm 11.8$ \\
\hline ML-PSV(EC) (mm/s) & $41.2 \pm 43.6$ \\
\hline $\operatorname{PSVM}(\mathrm{EC})\left(\mathrm{mm}^{2}\right)$ & $222.6 \pm 173.7$ \\
\hline \multicolumn{2}{|l|}{ Dynamic balance } \\
\hline BBS (score) & $41.4 \pm 5.2$ \\
\hline TUG (sec) & $21.7 \pm 4.1$ \\
\hline
\end{tabular}

Values are expressed as numbers (\%) or means \pm SD. MMSE-K: Korean version of the mini mental state examination

EO, eyes open; EC, eyes closed; AP-PSV, anteroposterior postural sway velocity; ML-PSV, mediolateral postural sway velocity; PSVM, postural sway velocity moment; BBS, Berg Balance Scale; TUG, Timed Up and Go test

mal walking speed, turn around, walk back to the chair, and sit back down on the chair. Use of assistive devices was permitted when necessary ${ }^{5)}$. All measurements, including postural sway and dynamic balance (BBS and TUG), were performed while the patients were in a rehabilitation ward, and the assessor was blinded.

The SPSS ver. 12.0 statistical software was used for all analyses. Descriptive statistics were used to describe patient characteristics after confirming normality. Descriptive statistics were used to describe patient characteristics. Correlations between postural sway under stable and unstable conditions and dynamic balance abilities (BBS and TUG) were assessed using Pearson's correlational coefficient. A significance level of 0.05 was set for all analyses. 
Table 2. Correlation between postural sway and dynamic balance $(\mathrm{N}=31)$

\begin{tabular}{clcccccc}
\hline & & $\begin{array}{c}\text { AP-PSV (EO) } \\
\mathrm{mm} / \mathrm{s}\end{array}$ & $\begin{array}{c}\text { ML-PSV (EO) } \\
\mathrm{mm} / \mathrm{s}\end{array}$ & $\begin{array}{c}\text { PSVM (EO) } \\
\mathrm{mm}^{2}\end{array}$ & $\begin{array}{c}\text { AP-PSV (EC) } \\
\mathrm{mm} / \mathrm{s}\end{array}$ & $\begin{array}{c}\text { ML-PSV (EC) } \\
\mathrm{mm} / \mathrm{s}\end{array}$ & $\begin{array}{c}\text { PSVM (EC) } \\
\mathrm{mm}^{2}\end{array}$ \\
\hline Stable & BBS (score) & -0.24 & -0.10 & 0.20 & -0.14 & -0.11 & 0.07 \\
condition & TUG (sec) & 0.10 & -0.01 & -0.21 & -0.06 & -0.07 & -0.24 \\
Unstable & BBS (score) & $-0.46^{* *}$ & -0.06 & 0.20 & $-0.42^{*}$ & -0.23 & $-0.50^{* *}$ \\
condition & TUG (sec) & 0.33 & -0.08 & 0.08 & 0.16 & 0.05 & 0.32 \\
\hline
\end{tabular}

PSVM, postural sway velocity moment; AP-PSV, anteroposterior postural sway velocity; ML-PSV, mediolateral postural sway velocity; BBS, Berg Balance Scale; TUG: Timed Up and Go test; EO, eyes open; EC, eyes closed $* \mathrm{p}<0.05, * * \mathrm{p}<0.01$

\section{RESULTS}

General characteristics and data concerning postural sway and dynamic balance ability of the subjects are summarized in Table 1.

The correlations between postural sway and dynamic balance in the stable and unstable conditions are summarized in Table 2. On the unstable surface (foam), no significant correlation was observed between postural sway and dynamic balance except for the BBS score and anteroposterior postural sway velocity in the eyes open condition $(r=-0.46, \mathrm{p}<0.01)$, anteroposterior postural sway velocity in the eyes closed condition $(r=-0.42, \mathrm{p}<0.05)$, and postural sway velocity moment $(r=-0.50, \mathrm{p}<0.01)$. However, in the stable condition, no significant correlation was observed between postural sway and dynamic balance.

\section{DISCUSSION}

The current study was conducted in order to investigate the relationship between postural sway and dynamic balance in post stroke patients. According to our main findings, no significant correlation was observed between postural sway and dynamic balance except between the BBS score and anteroposterior postural sway velocity in the eyes open condition, anteroposterior postural sway velocity in the eyes closed condition, and postural sway velocity moment on the unstable surface (foam). In addition, in the stable condition, no significant correlation was observed between postural sway and dynamic balance.

Postural control is defined as a complex skill involving interaction with sensory and motor systems, and postural control is essential and inevitable to maintenance of independent activities of daily living in stroke patients $\left.{ }^{12}, 13\right)$. Humans are swayed in several directions for maintenance of standing balance within the base of support, and a force platform is commonly used in assessment of postural sway ${ }^{14,15)}$. Through many previous studies ${ }^{3,16,17)}$, increases in postural sway have been shown to be associated with a reduction in balnace ability and weight trasfer and to lead to an increased incidence of falls. Chisholm et al. ${ }^{18)}$ reported an association of decreases in postural sway with functional movement. In addition, Niam et al. ${ }^{19)}$ reported negative correlation of postural sway with dynamic balance (BBS) in stroke patients.

In contrast, our findings showed no significant correlation between postural sway and dynamic balance. Accord- ing to previous studies investigating dynamic balance and postural sway ${ }^{10,20)}$, postural sway does not always mean poor balance. Increases in postural sway may not be associated with maintenance of dynamic postural stability. In stroke patients with damage to the central nervous system, body movements are made as they attempt to control their posture in the standing position and as they try to maintain their center of mass ${ }^{21)}$. Thus, the results of our study indicate that a decrease in postural sway does not necessarily reflect improvement of dynamic balance ability. We believe that this finding may be useful in balance rehabilitation for prevention of falls after stroke.

This study had some limitations. According to previous studies $^{22,23)}$, many factors can affect postural sway including the vestibular, somatosensory, and visual systems. In particular, postural control can be affected through fatigue in the musculature surrounding the ankles, knees, and hip ${ }^{24,25)}$. However, these factors were not investigated in this study. Thus, conduct of additional studies will be needed in order to fully understand the relation between postural sway and dynamic balance ability.

\section{REFERENCES}

1) Hayashi D, Gonçalves CG, Parreira RB, et al.: Postural balance and physical activity in daily life (PADL) in physically independent older adults with different levels of aerobic exercise capacity. Arch Gerontol Geriatr, 2012, 55: 480-485. [Medline] [CrossRef]

2) Horak FB: Postural orientation and equilibrium: what do we need to know about neural control of balance to prevent falls? Age Ageing, 2006, 35: ii7-ii11. [Medline] [CrossRef]

3) Geurts AC, de Haart M, van Nes IJ, et al.: A review of standing balance recovery from stroke. Gait Posture, 2005, 22: 267-281. [Medline] [CrossRef]

4) Blum L, Korner-Bitensky N: Usefulness of the Berg Balance Scale in stroke rehabilitation: a systematic review. Phys Ther, 2008, 88: 559-566. [Medline] [CrossRef]

5) Ng SS, Hui-Chan CW: The timed up \& go test: its reliability and association with lower-limb impairments and locomotor capacities in people with chronic stroke. Arch Phys Med Rehabil, 2005, 86: 1641-1647. [Medline] [CrossRef]

6) Era P, Schroll M, Ytting H, et al.: Postural balance and its sensory-motor correlates in 75-year-old men and women: a cross-national comparative study. J Gerontol A Biol Sci Med Sci, 1996, 51: M53-M63. [Medline] [CrossRef]

7) Nichols DS: Balance retraining after stroke using force platform biofeedback. Phys Ther, 1997, 77: 553-558. [Medline]

8) Kim JW, Eom GM, Kim CS, et al.: Sex differences in the postural sway characteristics of young and elderly subjects during quiet natural standing. Geriatr Gerontol Int, 2010, 10: 191-198. [Medline]

9) Lajoie Y, Gallagher SP: Predicting falls within the elderly community: comparison of postural sway, reaction time, the Berg balance scale and the Activities-specific Balance Confidence (ABC) scale for comparing fallers 
and non-fallers. Arch Gerontol Geriatr, 2004, 38: 11-26. [Medline] [CrossRef]

10) Cho KH, Lee KJ, Song CH: Virtual-reality balance training with a videogame system improves dynamic balance in chronic stroke patients. Tohoku J Exp Med, 2012, 228: 69-74. [Medline] [CrossRef]

11) $\mathrm{Ha} \mathrm{H}$, Cho K, Lee W: Reliability of the good balance system $\left({ }^{\circledR}\right)$ for postural sway measurement in poststroke patients. J Phys Ther Sci, 2014, 26 121-124. [Medline] [CrossRef]

12) de Oliveira CB, de Medeiros IR, Frota NA, et al.: Balance control in hemiparetic stroke patients: main tools for evaluation. J Rehabil Res Dev, 2008 45: 1215-1226. [Medline] [CrossRef]

13) Rosén E, Sunnerhagen KS, Kreuter M: Fear of falling, balance, and gai velocity in patients with stroke. Physiother Theory Pract, 2005, 21: 113 120. [Medline] [CrossRef]

14) Winter DA, Prince F, Frank JS, et al.: Unified theory regarding A/P and $\mathrm{M} / \mathrm{L}$ balance in quiet stance. J Neurophysiol, 1996, 75: 2334-2343. [Medline]

15) Woollacott MH, Shumway-Cook A, Nashner LM: Aging and posture control: changes in sensory organization and muscular coordination. Int J Aging Hum Dev, 1986, 23: 97-114. [Medline] [CrossRef]

16) Belgen B, Beninato M, Sullivan PE, et al.: The association of balance capacity and falls self-efficacy with history of falling in communitydwelling people with chronic stroke. Arch Phys Med Rehabil, 2006, 87: 554-561. [Medline] [CrossRef]

17) Shim $\mathrm{SH}$, Yu JH, Jung JH, et al.: Effects of dual-task performance on postural sway of stroke patients with experience of falls. J Phys Ther Sci, 2012, 24: 975-978. [CrossRef]

18) Chisholm AE, Perry SD, McIlroy WE: Inter-limb centre of pressure symmetry during gait among stroke survivors. Gait Posture, 2011, 33: 238-243. [Medline] [CrossRef]

19) Niam S, Cheung W, Sullivan PE, et al.: Balance and physical impairments after stroke. Arch Phys Med Rehabil, 1999, 80: 1227-1233. [Medline] [CrossRef]

20) Cho KH, Lee WH: Effect of treadmill training based real-world video recording on balance and gait in chronic stroke patients: a randomized controlled trial. Gait Posture, 2014, 39: 523-528. [Medline] [CrossRef]

21) Winstein CJ, Gardner ER, McNeal DR, et al.: Standing balance training: effect on balance and locomotion in hemiparetic adults. Arch Phys Med Rehabil, 1989, 70: 755-762. [Medline]

22) Gribble PA, Hertel J: Effect of lower-extremity muscle fatigue on postural control. Arch Phys Med Rehabil, 2004, 85: 589-592. [Medline] [CrossRef]

23) $\mathrm{Yu} \mathrm{JH}$, Jung JH, Cho $\mathrm{KH}$ : Changes in postural sway according to surface stability in post-stroke patients. J Phys Ther Sci, 2012, 24: 1183-1186. [CrossRef]

24) Davidson BS, Madigan ML, Nussbaum MA: Effects of lumbar extensor fatigue and fatigue rate on postural sway. Eur J Appl Physiol, 2004, 93: 183-189. [Medline] [CrossRef]

25) Park JN, Cho KH, Lee WH: Effect of jumping exercise on muscle strength and balance of elderly people: a randomized controlled trial. J Phys Ther Sci, 2012, 24: 1345-1348. [CrossRef] 